\title{
Microsatellite instability in patients with multiple primary cancers of the gastrointestinal tract
}

K Yamashita, Y Arimura, S Kurokawa, F Itoh, T Endo, K Hirata, A Imamura, M Kondo, T Sato, K Imai

First Department of Internal Medicine, Sapporo Medical University, Sapporo, Japan

K Yamashita

Y Arimura

S Kurokawa

F Itoh

T Endo

K Imai

First Department of Surgery, Sapporo Medical University, Sapporo, Japan

K Hirata

Department of Gastroenterology, Sapporo Kosei General Hospital, Sapporo,

Japan

A Imamura

Department of Surgery, Sapporo Kosei General

Hospital, Sapporo, Japan

M Kondo

Department of Clinical Pathology, Sapporo Kosei General Hospital, Sapporo, Japan

T Sato

Correspondence to: K Yamashita, First

Department of Internal

Medicine, Sapporo Medical

University, S1W16,

Chuo-ku, Sapporo, Japan.

Email:

kentaroh@wa2.so-net.ne.jp

Accepted for publication 21 December 1999

\begin{abstract}
Background-Little is known about the genetic alterations in multiple primary cancers of the gastrointestinal tract. Microsatellite instability (MSI) is frequently observed in hereditary non-polyposis colorectal cancer (HNPCC), and multiple primary cancers is a feature of this syndrome.

Aims-To identify MSI incidence, target gene mutation, and mismatch repair (MMR) protein status in patients with multiple primary cancers of the gastrointestinal tract.

Subjects-Fifty seven cancers from 22 Japanese patients with multiple primary cancers of the stomach, duodenum, colon, and rectum.

Methods-MSI was examined at 5-7 microsatellite loci. Mutation analysis for TGFßRII, IGFIIR, and BAX was performed in cancers with MSI. MMR protein status was examined by immunohistochemical analysis using a monoclonal antibody against $\mathrm{hMSH} 2$ and hMLH1.

Results-MSI was observed in 16 of 22 patients $(73 \%)$ and in 29 of 57 lesions (51\%). High frequency MSI (MSI-H) was found often in patients with multiple cancers in the same organ $(p=0.042)$, especially in multiple gastric cancer patients $(p=0.038)$. In contrast, patients with multiple cancers in different organs had a tendency to show low frequency MSI (MSI-L) or microsatellite stable (MSS) phenotype. Both target gene mutation and decreased expression of MMR protein were found only in seven lesions of three patients with MSI at more than four microsatellite loci. Conclusions-These results suggest that genetic instability may play an important role in the development of multiple gastrointestinal cancers but there may be different genetic alterations between multiple gastrointestinal cancers of the same and different organs.

(Gut 2000;46:790-794)
\end{abstract}

Keywords: microsatellite instability; multiple primary cancer; hereditary non-polyposis colorectal cancer

Gastric and colorectal cancer are the most common neoplasms in Japan. Almost 5\% of gastric and colorectal cancer patients develop other primary gastrointestinal cancers synchronously or metachronously. ${ }^{1}$ Genetic markers to identify high risk patients for multiple primary cancers of the gastrointestinal tract is important in clinical management and may lead to better prognosis.

Hereditary non-polyposis colorectal cancer (HNPCC) is an autosomally dominant hereditary syndrome caused by germline mutation of mismatch repair genes, such as hMSH2, hMLH1, hPMS1, hPMS2, or hMSH6/GTBP. Microsatellite instability (MSI) has been found in up to $90 \%$ of HNPCC. ${ }^{2}$ This syndrome is characterised clinically by early onset, predominantly right sided colorectal cancer, multiple colorectal cancers, and extracolonic cancers, including the stomach, urinary tract, uterus, or ovary. MSI has also been observed in approximately $15-30 \%$ of single sporadic gastric cancers ${ }^{3}$ and in 10-15\% of single sporadic colorectal cancers. ${ }^{56}$ But little is known about MSI or other genetic alterations in multiple primary cancers of the gastrointestinal tract. We hypothesised that MSI would be found frequently in multiple gastrointestinal cancer patients because this form of cancer is one of the features of HNPCC. If MSI is observed frequently in these individuals it may be a useful screening marker to detect a high risk group for multiple gastrointestinal cancers. Therefore, we examined MSI, target gene mutations, and mismatch repair protein status in patients with multiple primary cancers of the gastrointestinal tract. In addition, the pathogenesis of multiple gastrointestinal cancers is discussed.

\section{Materials and methods}

MATERIALS AND DNA PREPARATION

A total of 57 cancers and corresponding normal tissues, fixed with formalin and embedded in paraffin, were obtained from 22 Japanese patients with synchronous or metachronous multiple primary cancers of the stomach, duodenum, colon, and rectum. None of the 22 patients met the Amsterdam criteria for a diagnosis of HNPCC. ${ }^{7}$ Genomic DNA was microdissected and purified by proteinase $\mathrm{K}$ digestion and phenol-chloroform extraction as described previously. ${ }^{8}$ On examining the 4 $\mu \mathrm{m}$ sections stained with haematoxylin and eosin, cancer areas of $10 \mu \mathrm{m}$ sections stained with haematoxylin were microdissected carefully under a microscope. Normal cell contami-

Abbreviations used in this paper: MSI, microsatellite instability; MSS, microsatellite stable; HNPCC, hereditary non-polyposis colorectal cancer; MMR, mismatch repair; PCR polymerase chain reaction; SSCP, single strand conformation polymorphism. 
nation in the microdissected areas of tumour was thought to be less than approximately $20 \%$.

\section{MSI ANALYSIS}

The following seven microsatellite markers were analysed: two mononucleotide repeats (BAT-26, BAT-40), two dinucleotide repeats (D5S346, D17S250), two trinuculeotide repeats (D14S50, AR), and one tetranucleotide repeat (MYCL1). All sense primers were labelled at the 5' end with indodicarbocyanine (Cy5). Polymerase chain reaction (PCR) was performed as reported previously. ${ }^{9-11}$ Each PCR reaction mixture consisted of the following: $50 \mathrm{ng}$ of DNA, $1.0 \mathrm{mmol} / 1$ of $\mathrm{MgCl}_{2}, 200$ $\mu \mathrm{mol} / 1$ of dNTP mixture, $2 \mu \mathrm{l}$ of PCR buffer, 10 pmol of each primer, and $0.25 \mathrm{U}$ of Taq DNA polymerase (Takara, Tokyo, Japan). A total of $20 \mu \mathrm{l}$ of mixture was overlaid with mineral oil. The reaction tubes were placed in a thermal cycler (Perkin Elmer-Cetus, Branchburg, New Jersey, USA). PCR conditions were $95^{\circ} \mathrm{C}$ for five minutes followed by 35 cycles (denaturation for 30 seconds at $95^{\circ} \mathrm{C}$, annealing for one minute at $45-55^{\circ} \mathrm{C}$, and extension for one minute at $72^{\circ} \mathrm{C}$ ), and a final extension for 10 minutes at $72^{\circ} \mathrm{C}$. The PCR products were electrophoresed on $6 \%$ denaturing polyacrylamide gels using DNA sequencer (ALFwin and ALFexpress, Pharmacia Biotech, Uppsala, Sweden) and subsequent analysis was performed using the Fragment Manager software package (Pharmacia). PCR and electrophoresis were performed at least twice for each lesion. MSI was considered to be positive when new peaks were seen in the PCR of a tumour that was not found in those of the normal mucosa. In this report, MSI was stratified as follows. High frequency MSI (MSI-H) was defined as MSI in $\geqslant 30 \%$ of the markers examined whereas low frequency MSI (MSI-L) showed MSI in $<30 \%$ of the markers.

FLUORESCENT PCR-SINGLE STRAND CONFORMATION POLYMORPHISM ANALYSIS FOR MUTATIONS WITHIN THE CODING REGION OF THE TARGET GENE

If a tumour showed MSI, PCR-single strand conformation polymorphism (SSCP) analysis was performed for the detection of TGF $\beta$ RII (A10), IGFIIR (G8), and BAX (G8) mutations as described previously. ${ }^{12-14}$ The cell lines obtained from American Type Culture Collection (Rockville, Maryland, USA) were also analysed as mutation positive and negative controls: SW48 as mutated TGFßRII (A9) and IGFIIR (G7+G8) colonic cancer cell line, DU145 as mutated BAX $(\mathrm{G} 7+\mathrm{G} 9)$ prostatic cancer cell line, SKUT1B as mutated IGFIIR (G8+G9), and BAX (G8+G9) endometrial cancer cell line. Using sense primers labelled with Cy5, PCR was performed for 35 cycles, each consisting of denaturation for 30 seconds at $95^{\circ} \mathrm{C}$, annealing for one minute at $55^{\circ} \mathrm{C}$, and extension for one minute at $72^{\circ} \mathrm{C}$, followed by final extension for 10 minutes at $72^{\circ} \mathrm{C}$. The PCR products were denatured and electrophoresed on $8 \%$ nondenaturing polyacrylamide gels with or without $5 \%$ glycerol at 25,20 and $15^{\circ} \mathrm{C}$. Subsequent analysis was performed using the Fragment Manager software package.

IMMUNOSTAINING FOR hMSH2 AND hMLH1 All specimens were analysed immunohistochemically using the labelled streptavidinbiotin-peroxidase complex method with 3,3'-

Table 1 Results and profiles of all patients

\begin{tabular}{|c|c|c|c|c|c|c|c|c|c|c|c|c|c|c|c|c|c|c|c|}
\hline \multicolumn{10}{|c|}{ Same organ group } & \multicolumn{10}{|c|}{ Different organ group } \\
\hline \multirow[b]{2}{*}{ Patient } & \multirow[b]{2}{*}{ Age } & \multirow[b]{2}{*}{ Sex } & \multirow[b]{2}{*}{ Location } & \multirow[b]{2}{*}{$M S I$} & \multirow{2}{*}{$\begin{array}{l}\text { Unstable } \\
\text { loci } \\
\text { lexamined } \\
(\%)\end{array}$} & \multicolumn{3}{|c|}{ Mutation of } & \multirow{2}{*}{$\begin{array}{l}\text { Decreased } \\
\text { expression }\end{array}$} & \multirow[b]{2}{*}{ Patient } & \multirow[b]{2}{*}{ Age } & \multirow[b]{2}{*}{ Sex } & \multirow[b]{2}{*}{ Location } & \multirow[b]{2}{*}{$M S I$} & \multirow{2}{*}{$\begin{array}{l}\text { Unstable } \\
\text { loci } \\
\text { lexamined } \\
(\%)\end{array}$} & \multicolumn{3}{|c|}{ Mutation of } & \multirow{2}{*}{$\begin{array}{l}\text { Decreased } \\
\text { expression }\end{array}$} \\
\hline & & & & & & $T G F \beta$ & $I G F$ & $B A X$ & & & & & & & & $T G F \beta$ & $I G F$ & $B A X$ & \\
\hline \multicolumn{20}{|c|}{ Multiple gastric cancer } \\
\hline \multirow[t]{3}{*}{1} & 71 & $\mathrm{~F}$ & Stomach & - & $0 / 5(0)$ & & & & & 12 & 76 & M & Colon & $\mathrm{L}$ & $1 / 7(14)$ & - & - & - & \\
\hline & & & Stomach & $\mathrm{H}$ & $3 / 5(60)$ & - & - & - & & & & & Colon & $\mathrm{H}$ & $3 / 7(43)$ & - & - & - & \\
\hline & & & Stomach & - & $0 / 5(0)$ & & & & & & & & Colon & - & $0 / 7(0)$ & & & & \\
\hline \multirow[t]{4}{*}{2} & 80 & $\mathrm{~F}$ & Stomach & $\mathrm{H}$ & $5 / 5(100)$ & - & + & - & hMLH1 & & & & Colon & - & $0 / 7(0)$ & & & & \\
\hline & & & Stomach & $\mathrm{H}$ & $5 / 5(100)$ & + & - & + & hMLH1 & & & & Colon & - & $0 / 7(0)$ & & & & \\
\hline & & & Stomach & $\mathrm{H}$ & $4 / 5(80)$ & - & - & - & hMLH1 & & & & Duodenum & - & $0 / 7(0)$ & & & & \\
\hline & & & Stomach & $\mathrm{H}$ & $6 / 6(100)$ & - & + & - & hMLH1 & 13 & 60 & $M$ & Stomach & $\mathrm{L}$ & $1 / 7(14)$ & - & - & - & \\
\hline \multirow[t]{3}{*}{3} & 70 & M & Stomach & $\mathrm{H}$ & $3 / 5(60)$ & - & - & - & & & & & Stomach & $\mathrm{H}$ & $3 / 7(43)$ & - & - & - & \\
\hline & & & Stomach & $\mathrm{H}$ & $3 / 5(60)$ & - & - & - & & & & & Stomach & $\mathrm{L}$ & $2 / 7(29)$ & - & - & - & \\
\hline & & & Stomach & $\mathrm{H}$ & $4 / 5(80)$ & - & - & - & & & & & Stomach & - & $0 / 6(0)$ & & & & \\
\hline 4 & 65 & M & Stomach & $\mathrm{L}$ & 2/7 (29) & - & - & - & & & & & Colon & $\mathrm{L}$ & 2/7 (29) & - & - & - & \\
\hline & & & Stomach & $\mathrm{H}$ & $6 / 7(86)$ & - & - & - & hMLH1 & 14 & 67 & $M$ & Stomach & - & $0 / 5(0)$ & & & & \\
\hline 5 & 59 & M & Stomach & - & $0 / 7(0)$ & & & & & & & & Stomach & - & $0 / 5(0)$ & & & & \\
\hline & & & Stomach & - & $0 / 7(0)$ & & & & & & & & Stomach & - & $0 / 5(0)$ & & & & \\
\hline & & & & & & & & & & & & & Colon & $\mathrm{L}$ & $1 / 5(20)$ & - & - & - & \\
\hline Multipl & le colc & rectal & cancer & & & & & & & 15 & 51 & $\mathrm{~F}$ & Stomach & - & $0 / 7(0)$ & & & & \\
\hline 6 & 69 & M & Rectum & $\mathrm{H}$ & $3 / 7(43)$ & - & - & - & & & & & Colon & - & $0 / 7(0)$ & & & & \\
\hline & & & Rectum & $\mathrm{L}$ & $1 / 7(14)$ & - & - & - & & 16 & 62 & M & Stomach & $\mathrm{H}$ & $4 / 7(57)$ & - & - & + & hMSH2 \\
\hline 7 & 81 & M & Rectum & - & $0 / 7(0)$ & & & & & & & & Colon & $\mathrm{H}$ & $5 / 7(71)$ & - & + & - & hMSH2 \\
\hline & & & Colon & - & $0 / 7(0)$ & & & & & 17 & 69 & M & Stomach & - & $0 / 7(0)$ & & & & \\
\hline 8 & 59 & $M$ & Colon & $\mathrm{L}$ & $1 / 6(17)$ & - & - & - & & & & & Rectum & - & $0 / 7(0)$ & & & & \\
\hline & & & Colon & $\mathrm{L}$ & $1 / 6(17)$ & - & - & - & & 18 & 60 & $M$ & Stomach & $\mathrm{L}$ & $1 / 7(14)$ & - & - & - & \\
\hline 9 & 63 & M & Rectum & - & $0 / 6(0)$ & & & & & & & & Rectum & - & $0 / 7(0)$ & & & & \\
\hline & & & Colon & - & $0 / 6(0)$ & & & & & 19 & 73 & $\mathrm{~F}$ & Stomach & $\mathrm{L}$ & $1 / 7(14)$ & - & - & - & \\
\hline 10 & 46 & $\mathrm{~F}$ & Rectum & - & $0 / 6(0)$ & & & & & & & & Colon & - & $0 / 6(0)$ & & & & \\
\hline & & & Colon & $\mathrm{H}$ & $2 / 6(33)$ & - & - & - & & 20 & 70 & $M$ & Stomach & - & $0 / 7(0)$ & & & & \\
\hline 11 & 70 & $\mathrm{~F}$ & Rectum & - & $0 / 7(0)$ & & & & & & & & Rectum & $\mathrm{L}$ & $1 / 7(14)$ & - & - & - & \\
\hline & & & Colon & $\mathrm{L}$ & $2 / 7(29)$ & - & - & - & & 21 & 69 & $M$ & Stomach & $\mathrm{L}$ & $1 / 5(20)$ & - & - & - & \\
\hline & & & & & & & & & & & & & Rectum & - & $0 / 6(0)$ & & & & \\
\hline & & & & & & & & & & 22 & 69 & $\mathrm{M}$ & Stomach & - & $0 / 6(0)$ & & & & \\
\hline & & & & & & & & & & & & & Rectum & - & $0 / 6(0)$ & & & & \\
\hline
\end{tabular}



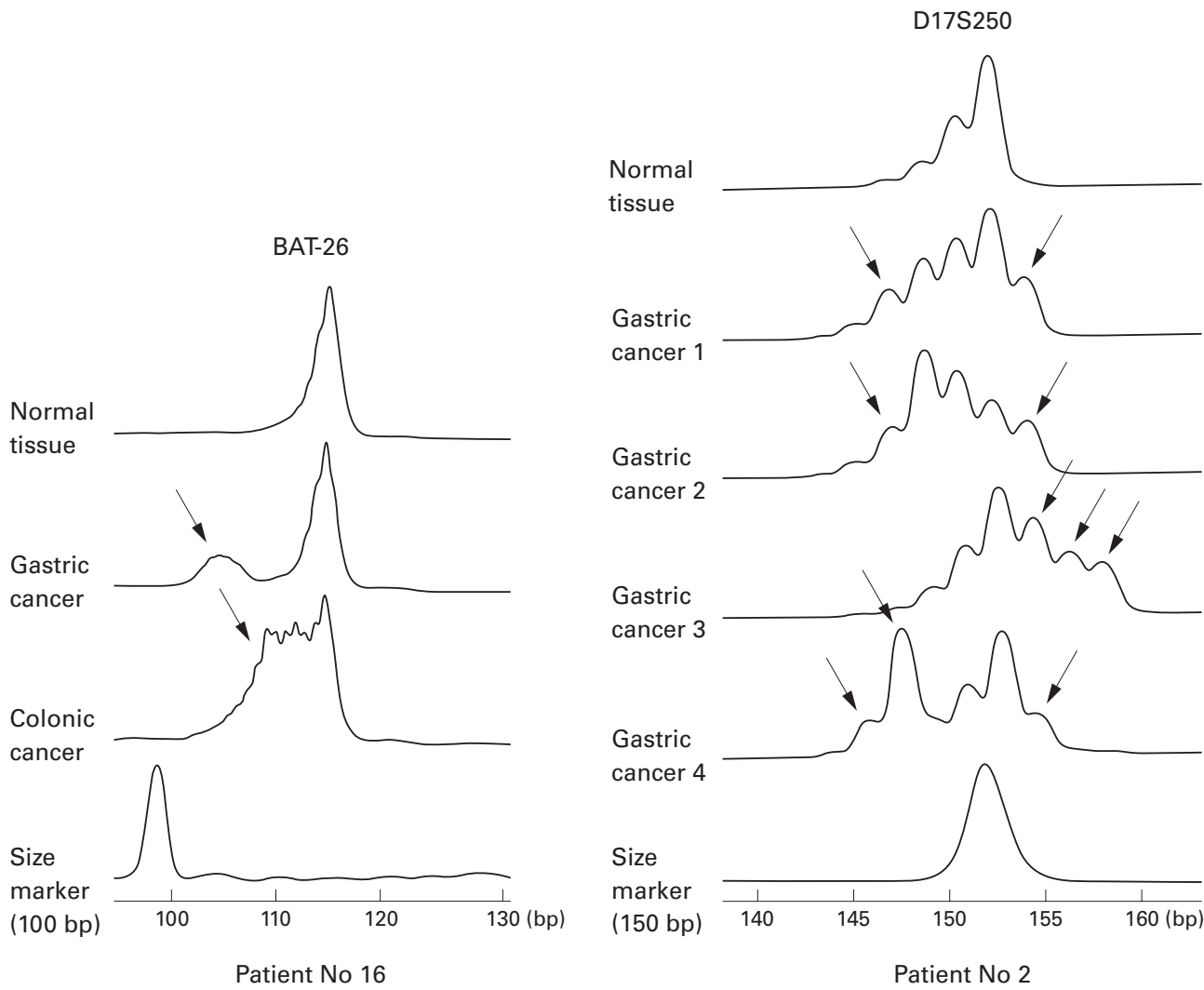

Figure 1 Typical results of microsatellite instability (MSI). MSI is seen as extra peaks in tumours (arrows) compared with normal tissues. In patient No 16, both gastric and colonic cancers showed MSI of BAT-26 (left). In patient No 2, all four gastric cancers showed MSI of D17S250 (right).

diaminobenzidine. Thick sections $(4 \mu \mathrm{m})$ were deparaffinised in xylene, dehydrated in ethanol, and washed in phosphate buffered saline. Sections were autoclaved in target retrieval solution (Dako, Carpinteria, California, USA). After blocking endogenous peroxidase activity with peroxidase blocking reagent (Dako), sections were incubated overnight at $4^{\circ} \mathrm{C}$ with mouse monoclonal antibody against hMSH2 and hMLH1 (diluted 1:100) (Calbiochem, La Jolla, California, USA). Haematoxylin was used as a counterstain. Infiltrating lymphocytes as well as normal gastric or colonic epithelium next to the tumour served as internal positive controls.

STATISTICAL ANALYSIS

Statistical analysis was performed using the $\chi^{2}$ test; $\mathrm{p}<0.05$ was considered statistically significant.

Results

A total of 57 cancers from 22 Japanese multiple primary cancer patients (six women) were analysed for MSI at 5-7 microsatellite loci. The 57

Table 2 Microsatellite instability (MSI) in all 22 patients and 57 cancers. Patients who had at least one lesion with MSI were considered to have the MSI phenotype

\begin{tabular}{lll}
\hline MSI & Patients (\%) & Cancers (\%) \\
\hline MSI & $16(73)$ & $29(51)$ \\
MSI-H & - & $15(26)$ \\
MSI-L & - & $14(25)$ \\
MSS & $6(27)$ & $28(49)$ \\
Total & 22 & 57
\end{tabular}

MSI-H, MSI-L, high and low frequency microsatellite instability, respectively. MSS, microsatellite stable. lesions consisted of 29 gastric cancers, 27 colorectal cancers, and one duodenal cancer. Of the 22 patients, 11 had multiple primary cancers in the same organ (same organ group: five multiple gastric cancer patients and six multiple colorectal cancer patients) and 11 had multiple primary cancers in different organs (different organ group). Mean age at diagnosis was similar in each group (66.6 $v 66.0$ years). All patients had developed multiple primary cancers synchronously except for one who developed five colonic and a duodenal cancer metachronously (patient No 12). Results are summarised in table 1 .

MSI

Representative results for MSI are shown in fig 1 . MSI was observed in 16 of 22 patients $(73 \%)$ and in 29 of 57 cancers (51\%) (table 2). Of the 29 cancers with MSI, 15 (26\%) showed MSI-H and $14(25 \%)$ MSI-L. Twelve of 16 patients with MSI (75\%) showed heterogeneity of microsatellite alterations, for example, one lesion showed the MSI-H phenotype but the

Table 3 Proportion of cancers with microsatellite instability (MSI) in multiple primary cancers in the same and different organ subgroups

\begin{tabular}{lll}
\hline MSI & $\begin{array}{l}\text { Same organ } \\
\text { group }(\%)\end{array}$ & $\begin{array}{l}\text { Different organ } \\
\text { group (\%) }\end{array}$ \\
\hline MSI-H & $11(42)$ & $4(13)$ \\
MSI-L & $5(19)$ & $9(29)$ \\
MSS & $10(38)$ & $18(58)$ \\
Total & 26 & 31
\end{tabular}

$\mathrm{p}=0.042, \chi^{2}=6.305$.

MSS, microsatellite stable. 


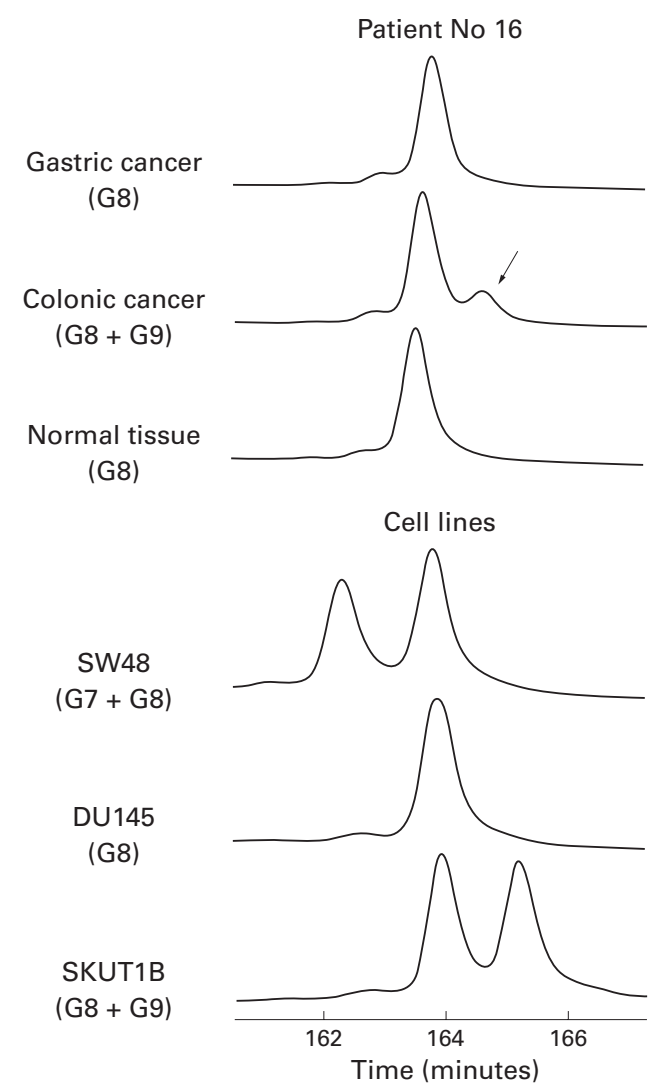

Figure 2 Typical results of target gene mutations. SW48 and SKUT1B are known to have mutated IGFIIR $(G 7+G 8$ and $G 8+G 9$, respectively). DU145 have wild type (G8). In patient No 16, colonic cancer showed mutated IGFIIR (G8+G9, arrow).

other the MSI-L or MSS phenotype in the same patient (table 1).

MSI-H was seen in 11 of $26(42 \%)$ lesions from the same organ group but in four of 31 $(13 \%)$ lesions from the different organ group. In contrast, MSI-L and MSS were seen in five $(19 \%)$ and $10(38 \%)$ lesions from the same organ group and in nine $(29 \%)$ and $18(58 \%)$ lesions from the different organ group, respectively. There was a significant difference

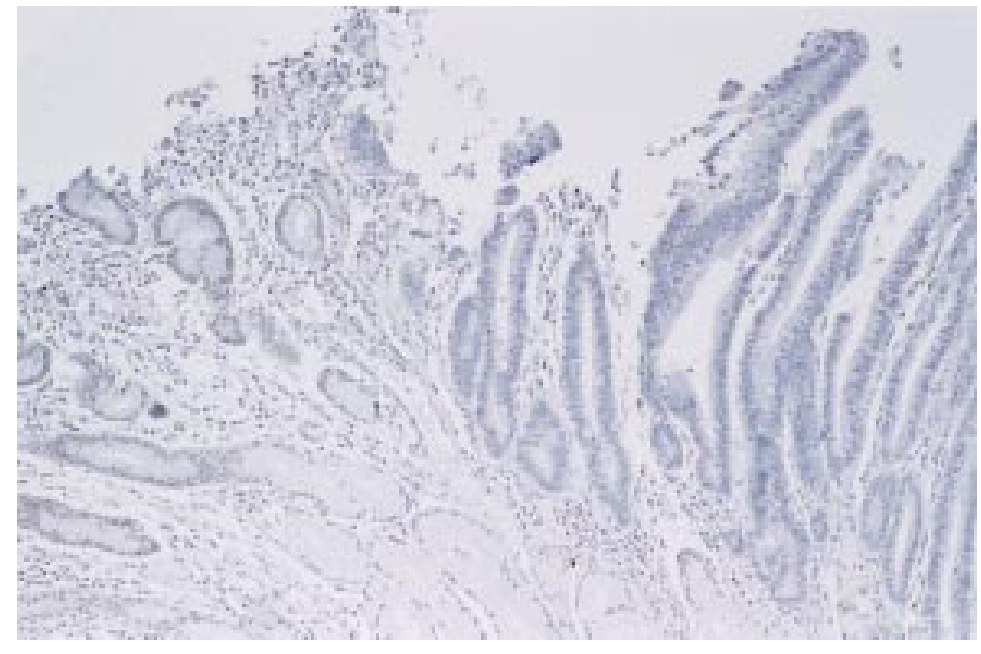

Figure 3 Immunostaining for hMSH2 in gastric cancer from patient No 16. Normal gastric epithelium (left) and infiltrating inflammatory cells were stained, but in cancer tissue (right) hMSH2 protein expression was very weak.
Table 4 Proportion of cancers with microsatellite instability (MSI) in multiple gastric cancers and multiple colorectal cancers

\begin{tabular}{lll}
\hline MSI & $\begin{array}{l}\text { Multiple gastric } \\
\text { cancer (\%) }\end{array}$ & $\begin{array}{l}\text { Multiple colorectal } \\
\text { cancer }(\%)\end{array}$ \\
\hline MSI-H & $9(64)$ & $2(17)$ \\
MSI-L & $1(7)$ & $4(33)$ \\
MSS & $4(29)$ & $6(50)$ \\
Total & 14 & 12 \\
\hline
\end{tabular}

$\mathrm{p}=0.038, \chi^{2}=6.539$.

MSS, microsatellite stable.

between the two groups $\left(\mathrm{p}=0.042, \chi^{2}=6.305\right)$ (table 3).

In the same organ group, MSI-H was seen in nine of $14(64 \%)$ lesions from multiple gastric cancer patients and in two of $12(17 \%)$ lesions from multiple colorectal cancer patients. But MSI-L and MSS were seen in one $(7 \%)$ and four $(29 \%)$ lesions from multiple gastric cancer patients and in four (33\%) and six (50\%) lesions from multiple colorectal cancer patients. There was also a significant difference between each subgroup $\left(\mathrm{p}=0.038, \chi^{2}=6.539\right)$ (table 4). There was no significant association between MSI and clinicopathological features (age, sex, location, histology, depth, vessel invasion, or stage).

TARGET GENE MUTATION

The representative results of target gene mutations are shown in fig 2 . Of 29 cancers with MSI, only five cancers from two patients (patient Nos 2 and 16) showed mutations of TGF $\beta$ RII, IGFIIR, or BAX. All of the five lesions showed MSI at more than four microsatellite loci (table 1).

\section{EXPRESSION OF MISMATCH REPAIR (MMR)} PROTEIN

The representative results of decreased expression of MMR protein are shown in fig 3. Of all the 57 cancers, five cancers from two patients (patient Nos 2 and 4) and two cancers from one patient (patient No 16) showed decreased expression of $\mathrm{hMLH} 1$ and $\mathrm{hMSH} 2$ protein, respectively. All of the seven lesions also showed MSI at more than four microsatellite loci (table 1).

\section{Discussion}

Our results suggest that genetic instability may play an important role in the development of multiple primary cancers of the gastrointestinal tract. MSI has been found in up to $90 \%$ of HNPCC. ${ }^{2}$ MSI has also been observed in approximately $15-30 \%$ of single sporadic gastric cancers ${ }^{34}$ and in 10-15\% of single sporadic colorectal cancers. ${ }^{56}$ Therefore, it is thought that a defective MMR system may cause not only HNPCC but also, in part, single sporadic cancers. Also, multiple primary cancers, such as gastric, colorectal, endometrial, and urinary tract, is one of the features of HNPCC. Therefore, we hypothesised that MSI would be found frequently in multiple gastrointestinal cancer patients. But there are few reports describing multiple primary cancers and MSI. Horii et al have reported that MSI was observed in $89 \%$ of patients with 
multiple primary cancers of various organs. ${ }^{15}$ Brown et al have shown that MSI was present in 23 of $69(33 \%)$ patients who had colorectal cancer and one other primary cancer from the HNPCC spectrum. ${ }^{5}$ The major problem of these reports is that most did not discriminate between multiple primary cancers of the same organ from those of different organs. Also, this difference in MSI frequency may be due to cancer location, number and type of examined microsatellite markers, or definition of MSI.

It is still unclear which and how many microsatellite markers should be analysed and what percentage of unstable loci defines a tumour as MSI positive. Based on previous reports $^{91617}$ we selected seven microsatellite markers and stratified MSI into MSI-H and MSI-L. In this study MSI in multiple gastrointestinal cancer patients was observed more frequently than in those with single primary gastric or colorectal cancer reported previously. ${ }^{3-6} 15$ Interestingly, MSI-H was seen more frequently in the same organ group, especially in multiple gastric cancer patients, than in the different organ group. Lesions from the different organ group tended to show the MSI-L or MSS phenotype. In addition, both target gene mutations and decreased expression of MMR protein were found only in lesions with instability at more than four microsatellite loci. From these results we suggest that there may be considerably different genetic changes between the same and different organ groups, and that there must be some sporadic multiple gastrointestinal cancer patients with a defective MMR system. But in many other MSI positive cancers, especially the MSI-L phenotype, deficiency of the MMR system was not proved. Sengupta et al have reported MSI in 17 of 24 cancers from patients with metachronous colorectal cancers but most had a low level of MSI. ${ }^{18}$ Although data are not shown, MSI was found more frequently in triand tetranucleotide repeat markers than in mono- and dinucleotide. In addition, $90 \%$ of the lesions with the MSI-L phenotype showed instability of MYCL1 (tetra) or AR (tri). These tendencies have not been reported previously in HNPCC. ${ }^{16}{ }^{17}$ Some alterations in the MMR system which are not seen in HNPCC, such as subtle somatic mutations that could not be detected by immunohistochemistry or mutation of other unknown genes, may also be involved in the development of sporadic multiple gastrointestinal cancers. It has been shown that mutation of GTBP resulted in a relatively low level of MSI. ${ }^{19}$ These MMR gene mutations may be reflected in MSI-L or frequent alteration of tri- and tetranucleotide repeats. Furthermore, $75 \%$ of patients with the MSI phenotype showed inter-tumour heterogeneity of MSI. Each tumour in these patients may have different genetic changes and there may be other carcinogenic processes than a defective MMR system in multiple gastrointestinal cancers.
MSI is thought to play an important role in the development of multiple primary cancers of the gastrointestinal tract. MSI analysis is rapid and inexpensive. Although analysis for mutation of various MMR genes is required in MSI positive patients, it is not practical in most general hospitals. MSI may be a useful screening marker to detect a high risk group for second primary cancer in some patients with sporadic single gastric and colorectal cancers. The clinical implications of gastric or colorectal cancers with MSI-L are still unclear. But even if sporadic, multiple gastrointestinal cancer patients with the MSI-H phenotype and target gene mutation or decreased expression of MMR protein must have a mutated MMR system. Further study of not only gastrointestinal cancers but also of other primary cancers, especially those seen in HNPCC, is recommended.

1 Tomoda $\mathrm{H}$, Taketomi A, Baba $\mathrm{H}$, et al. Multiple primary colorectal and gastric carcinoma in Japan. Oncol Rep 1998;5:147-9.

2 Liu B, Parsons R, Papadopoulos N, et al. Analysis of mismatch repair genes in hereditary nonpolyposis colorectal cancer patients. Nat Med 1996;2:169-74.

3 Strickler JG, Zheng J, Shu Q, et al. p53 mutations and microsatellite instability in sporadic gastric cancer: when guardians fail. Cancer Res 1994:54:4750-5.

4 Chon JM, Fukuyama M, Hayashi Y, et al. Microsatellite instability in the progression of gastric carcinoma. Cancer Res 1994;54:4595-7.

5 Brown SR, Finan PJ, Hall NR, et al. Incidence of DNA replication errors in patients with multiple primary cancers. Dis Colon Rectum 1998;41:765-9.

6 Aaltonen LA, Peltomaki P, Mecklin J-P, et al. Replication errors in benign and malignant tumours from hereditary nonpolyposis colorectal cancer patients. Cancer Res 1994; 54:1645-8.

7 Vasen HF, Mecklin J-P, Meerakhan P, Lynch HT. The international collaborative group on hereditary nonpolyposis colorectal cancer. Dis Colon Rectum 1991;34:424-5.

8 Goelz SE, Hamilton SR, Vogelstein B. Purification of DNA from formaldehyde fixed and paraffin embedded human issue. Biochem Biophys Res Commun 1985;130:118-26.

9 Hoang J-M, Cottu PH, Thuille B, et al. BAT-26, an indicator of the replication error phenotype in colorectal cancers and cell lines. Cancer Res 1997;57:300-3.

10 Dietmaier W, Wallinger S, Bocker T, et al. Diagnostic microsatellite instability: definition and correlation with mismatch repair protein expression. Cancer Res 1997;57:474956.

11 Mutter GL, Boynton KA. PCR bias in amplification of androgen receptor alleles, a trinucleotide repeat marker used in clonality studies. Nucleic Acids Res 1995;23:141118.

12 Markowitz S, Wang J, Myeroff L, et al. Inactivation of the type II TGF- $\beta$ receptor in colon cancer cells with microsatellite instability. Science 1995;268:1336-8.

13 Souza RF, Appeal R, Yin J, et al. Microsatellite instability in the insulin-like growth factor II receptor gene in gastrointestinal tumours. Nat Genet 1996;14:255-7.

14 Rampino N, Yamamoto H, Ionov Y, et al. Somatic frameshift mutations in the BAX gene in colon cancers of the microsatellite mutator phenotype. Science 1997;275: 967-9.

15 Horii A, Han H-J, Shimada M, et al. Frequent replication errors at microsatellite loci in tumors of patients with multiple primary cancers. Cancer Res 1994;54:3373-5.

16 Dietmaier W, Wallinger S, Bocker T, et al. Diagnostic microsatellite instability: definition and correlation with mismatch repair protein expression. Cancer Res 1997;57:474956.

17 Boland CR, Thibodeau SN, Hamilton SR, et al. A National Cancer Institute workshop on microsatellite instability for cancer detection and familial predisposition: development of international criteria for the determination of microsatellite instability in colorectal cancer. Cancer Res 1998;58: 5248-57.

18 Sengupta SB, Yiu CY, Boulos PB, et al. Genetic instability in patients with metachronous colorectal cancers. Br F Surg 1997;84:996-1000.

19 Papadopoulos N, Nicolaides NC, Liu B, et al. Mutations of GTBP in genetically unstable cells. Science 1995;9:10-11. 